\title{
An Overview of VPAC Receptors in Rheumatoid Arthritis: Biological Role and Clinical Significance
}

\author{
Rosa P. Gomariz ${ }^{1 \star \dagger}$, Yasmina Juarranz ${ }^{1 \dagger}$, Mar Carrión ${ }^{1}$, Selene Pérez-García ${ }^{1}$, \\ Raúl Villanueva-Romero ${ }^{1}$, Isidoro González-Álvaro ${ }^{2}$, Irene Gutiérrez-Cañas ${ }^{1}$, \\ Amalia Lamana ${ }^{1,2}$ and Carmen Martínez ${ }^{1 \dagger}$ \\ 1 Departamento de Biología Celular, Facultad de Biología y Facultad de Medicina, Universidad Complutense de Madrid, \\ Madrid, Spain, ${ }^{2}$ Servicio de Reumatología, Hospital Universitario de la Princesa, Instituto de Investigación Sanitaria la \\ Princesa (IIS-IP), Madrid, Spain
}

The axis comprised by the Vasoactive Intestinal Peptide (VIP) and its G protein-coupled receptors (GPCRs), VPAC1, and VPAC2, belong to the B1 family and signal through Gs

OPEN ACCESS

Edited by:

Leo T. O. Lee,

University of Macau, China

Reviewed by:

James Waschek,

University of California, Los Angeles,

United States

Terry Moody,

National Cancer Institute (NCl),

United States

*Correspondence:

Rosa P. Gomariz

gomariz@ucm.es

tThese authors have contributed equally to this work

Specialty section:

This article was submitted to Neuroendocrine Science,

a section of the journal

Frontiers in Endocrinology

Received: 25 June 2019 Accepted: 09 October 2019 Published: 22 October 2019

Citation:

Gomariz RP, Juarranz Y, Carrión M, Pérez-García $S$, Villanueva-Romero $R$, González-Álvaro I, Gutiérrez-Cañas I, Lamana A and Martínez C (2019) An

Overview of VPAC Receptors in Rheumatoid Arthritis: Biological Role and Clinical Significance.

Front. Endocrinol. 10:729.

doi: 10.3389/fendo.2019.00729 or Gq proteins. VPAC receptors seem to preferentially interact with Gs in inflammatory cells, rather than Gq, thereby stimulating adenylate cyclase activity. CAMP is able to trigger various downstream pathways, mainly the canonical PKA pathway and the non-canonical CAMP-activated guanine nucleotide exchange factor (EPAC) pathway. Classically, the presence of VPACs has been confined to the plasma membrane; however, VPAC1 location has been described in the nuclear membrane in several cell types such as activated Th cells, where they are also functional. VPAC receptor signaling modulates a number of biological processes by tipping the balance of inflammatory mediators in macrophages and other innate immune cells, modifying the expression of TLRs, and inhibiting MMPs and the expression of adhesion molecules. Receptor signaling also downregulates coagulation factors and acute-phase proteins, promotes Th2 over Th1, stimulates Treg abundance, and finally inhibits a pathogenic Th17 profile. Thus, the VIP axis signaling regulates both the innate and adaptive immune responses in several inflammatory/autoimmune diseases. Rheumatoid arthritis (RA) is a complex autoimmune disease that develops on a substrate of genetically susceptible individuals and under the influence of environmental factors, as well as epigenetic mechanisms. It is a heterogeneous disease with different pathogenic mechanisms and variable clinical forms between patients with the same diagnosis. The knowledge of VIP signaling generated in both animal models and human ex vivo studies can potentially be translated to clinical reality. Most recently, the beneficial effects of nanoparticles of VIP self-associated with sterically stabilized micelles have been reported in a murine model of RA. Another novel research area is beginning to define the receptors as biomarkers in RA, with their expression levels shown to be associated with the activity of the disease and patients-reported impairment. Therefore, VPAC expression together VIP genetic variants could allow patients to be stratified at the beginning of the disease with the purpose of guiding personalized treatment decisions.

Keywords: VPAC receptors, vasoactive intestinal peptide, rheumatoid arthritis, inflammation, autoimmunity, prognosis biomarker 


\section{INTRODUCTION}

Rheumatoid arthritis (RA) is a chronic autoimmune disease that causes joint inflammation and cartilage and bone destruction. RA affects $1 \%$ of the population worldwide and it is associated with damage of physical condition and quality of life. RA progresses in genetically susceptible individuals, under the effect of environmental factors, as well as with the contribution of epigenetic mechanisms. Vasoactive Intestinal Peptide (VIP) and its G protein-coupled receptors (GPCRs), VPAC1, and VPAC2, shape an axis signaling that regulates both the innate and immune response in several inflammatory/autoimmune diseases.

In the following sections, we will describe its therapeutic role in animal models of RA and its potential as a biomarker for the stratification of patients, contributing to the improvement of the development of personalized therapies.

\section{VPAC RECEPTORS: STRUCTURE, SIGNAL TRANSDUCTION, CELLULAR LOCALIZATION, AGONIST/ANTAGONIST MOLECULES, AND DETECTION}

VIP is a broadly distributed neuropeptide with known immunomodulatory attributes. VIP can act through three receptors: VIP acts almost exclusively through two high affinity receptors: VPAC1 and VPAC2. A third receptor, PAC1, poorly binds VIP in most physiological contexts, acting primarily by binding to the related ligand PACAP. In RA, VIP expression has been reported in nerve endings and in other cell types in the inflamed area, and it has been shown to actively modulate immune responses in experimental arthritis. In this regard, VIP released from sensory axonal terminals interacts with other molecules produced by nearby neutrophils, macrophages, and other immune and endothelial cells (1). Lymphocytes and synovial fibroblasts (SF) also produced and released VIP (2-5).VPAC1 and VPAC2 belong to the B1 family of GPCRs. $\mathrm{PAC} 1$, along with the secretin receptor, the glucagon receptor, the parathyroid hormone receptors and several others, are also found in this family. The members of this GPCR family share some specific characteristics $(6,7)$ : (i) the presence of a large $\mathrm{N}$-terminal ectodomain containing six highly conserved cysteine residues connected by three disulfide bridges; (ii) the $\mathrm{N}$-terminal acting as the major binding site for its natural peptide ligand; (iii) the existence of a signal peptide; (iv) the presence of N-glycosylation sites; (v) the lack of archetypical family A GPCR motifs such as E/D-R-Y or NP-xx(x)-Y; and (vi) the presence of many introns in their gene organization. This last point indicates that alternative splicing events could arise within VPAC receptors, however, although there is some evidence for the presence of splice variants of the VPAC1 and VPAC2 receptors, their functional significance is not yet clear (8). Studies with $\mathrm{CHO}$ cell line indicate that these receptors can also form oligomeric complexes, like other GRPRs, VPAC1 receptor is able to homodimerize and heterodimerize with VPAC2 or the secretin receptor (9). This oligomerization does not affect the recognition of ligands nor the function of the receptors (10).
It has been proposed that the interaction between natural ligands and VPAC receptors follows the "two-site" model, in the same way as in other members of the B1 family $(6,7)$. In this model, the central and C-terminal parts of the peptide ligand are trapped by the N-terminal of the receptor, which ensures correct ligand positioning. Binding of residues 1-6 of the ligand to the extracellular loops and transmembrane helices leads to receptor activation. To determine this, most studies have used VIP as the natural ligand and VPAC1 as the receptor $(11,12)$.

VPAC receptors signal through $\mathrm{Gs}$ or $\mathrm{Gq}$ proteins, class $\mathrm{B}$ receptors in general demonstrate greater potency in cAMP than IP3 generation, but this depends on cell type. In inflammatory cells, VPAC have greater affinity for G $\alpha$ s than $\mathrm{G} \alpha \mathrm{q}$, indicating that VPAC receptors preferentially stimulate adenylyl cyclase activity. In addition, it has been demonstrated in cell lines that these receptors can also interact with non-G proteins, which are termed "accessory proteins" or "GPCR interacting proteins (GIPs)," such as RAMPs or PDZ-containing proteins $(6,7,13,14)$. This interaction can modulate several properties of VPAC receptors including their ability to interact with $G$ proteins or their agonist-induced internalization. As mentioned above, adenylyl cyclase activation and the subsequent increase in cAMP levels is the main signaling pathway of VPAC receptors. However, cAMP is able to trigger various downstream pathways, mainly the canonical PKA pathway and the non-canonical cAMP-activated guanine nucleotide exchange factor (EPAC) pathway. Depending on the cell type, EPAC and PKA may act independently, synergistically, or may oppose each other regulating specific cellular functions (15). In addition to the PKAdependent pathway, it has been shown that VPAC receptors can also activate the PKA-independent pathway in several cell types $(16,17)$. On the other hand, binding of G $\alpha \mathrm{q}$ to VPAC is involved in the activation of the phospholipase C (PLC) pathway, stimulating protein kinase $\mathrm{C}(\mathrm{PKC})$ and promoting release of $\mathrm{Ca}^{2+}$ from the endoplasmic reticulum $[(8,10)$; Figure 1].

VPAC receptors, as with other GPCRs, are synthesized by the protein secretory pathway and their expression and trafficking are under co- and post-translational quality control to ensure that only proper VPAC receptors reach the cell surface (24). These receptors can also undergo internalization by homologous or heterologous desensitization $(25,26)$. In regards to the VPAC1 receptor, the internalization from plasma membrane by endosomes is induced by its own ligand, VIP. In addition to the plasma or endosome membranes, the intracellular position of functional GPCRs now broadly accepted by the scientific community $(27,28)$. The presence of VPAC1 receptor has been described in intracellular compartments, such as the nuclear membrane in different cells, as human breast cell lines, glioma cell lines or activated ex vivo Th lymphocytes, where they are also functional $(17,29-31)$. In this sense, the palmitoylation of the Nterminal extracellular Cys37 of the VPAC1 receptor induced by VIP mediates the nuclear translocation of this receptor (31). The trafficking of the VPAC1 receptor from the plasma membrane to the nuclear membrane could be related to the fact that the peptide sequence of this receptor has a nuclear localization signal sequence in its intracytoplasmic C-terminal, not found in the VPAC2 receptor (30). In this sense, the presence of VPAC2 


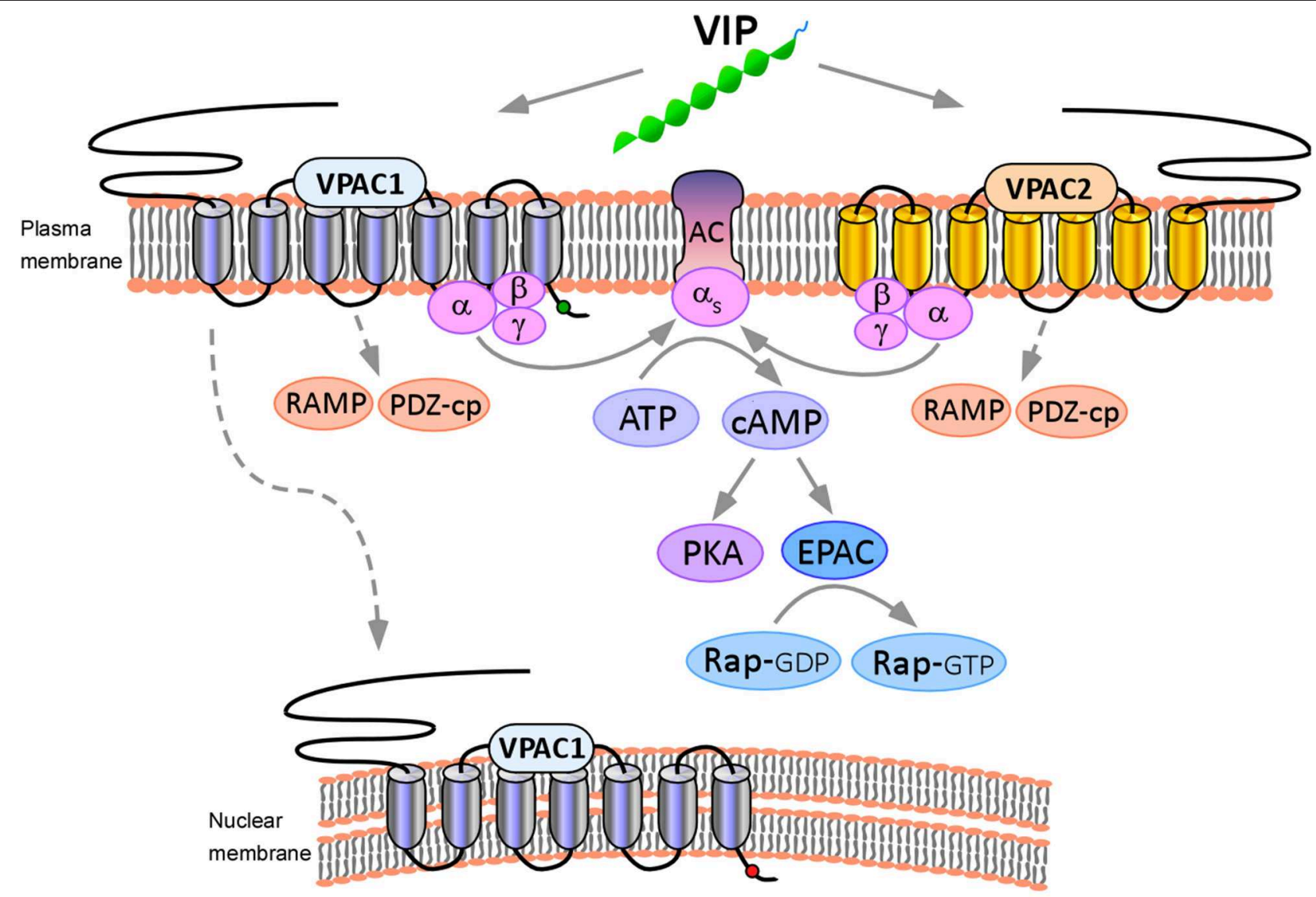

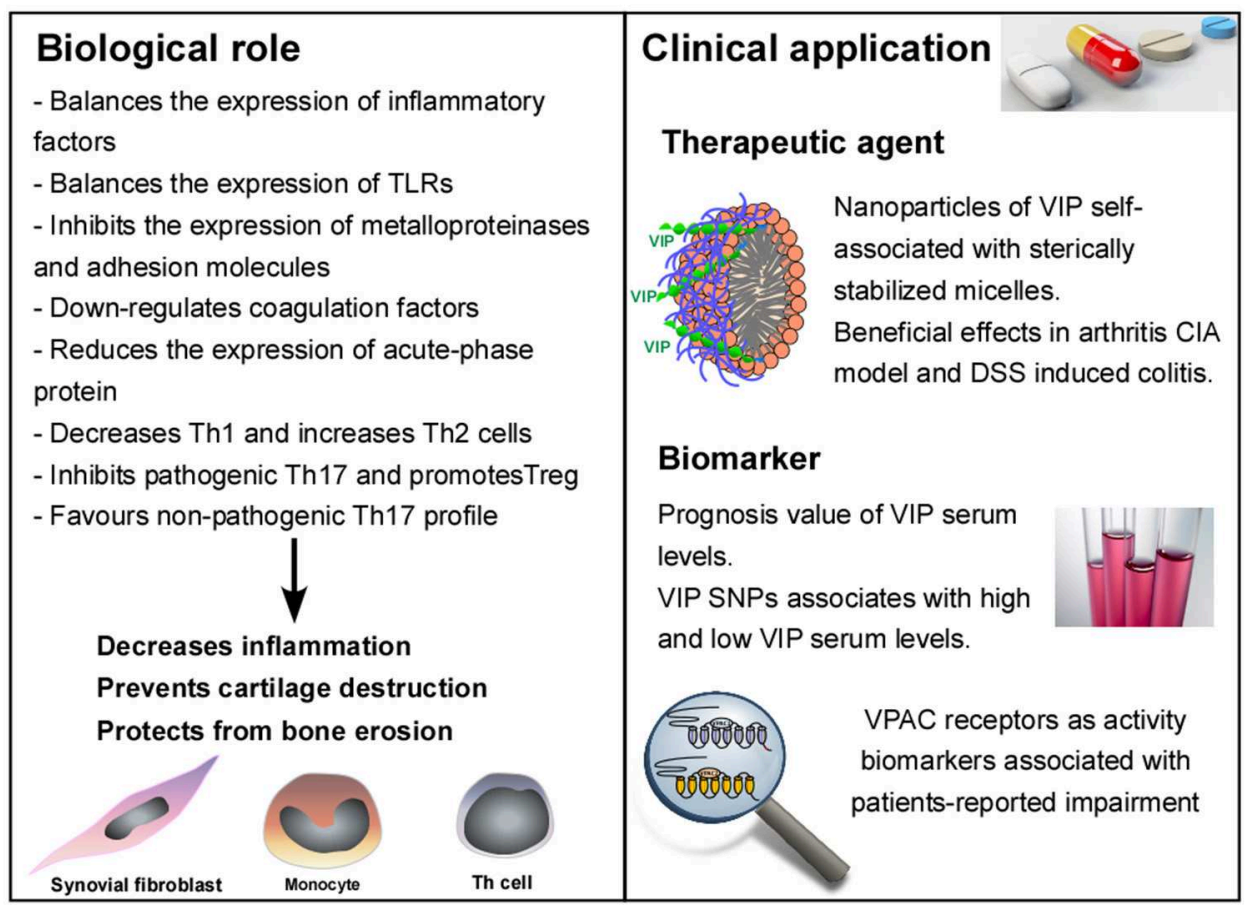

FIGURE 1 | Functional consequences of VPAC receptors signaling. VIP binds both, VPAC1 and VPAC2. VPAC receptors have greater affinity for Gas than Gaq, indicating that VPAC receptors preferentially stimulate adenylyl cyclase (AC) activity, increasing cAMP levels and triggering downstream pathways, mainly the canonical PKA pathway and the non-canonical cAMP-activated guanine nucleotide exchange factor (EPAC) pathway. Moreover, these receptors can also interact with accessory 
FIGURE 1 | GPCR interacting proteins (GIPs), such as RAMPs or PDZ-containing proteins (PDZ-cp). In addition, VPAC1 is also able to translocate to nucleus. Activation of VPAC receptors signaling modulates a number of biological processes, which eventually lead to the decrease of the inflammation, cartilage destruction and bone erosion. In relation to the clinical application, it has been reported the beneficial effects of nanoparticles of VIP self-associated with sterically stabilized micelles (SSMs) in collagen-induced arthritis (CIA) murine model $(18,19)$ and DSS induced colitis $(20)$. We have also demonstrated the prognosis value of VIP serum levels and VIP genetic variants. Moreover, VPAC receptors expression has been described as activity biomarkers associated with patients-reported impairment (21-23).

in intracellular locations other than endosomes has not yet been described.

The development of selective agonists or antagonists for GPCR is essential for studying these receptors, both from research and pharmacological points of view. These molecules must possess ligand-selectivity, cross-species reactivity and receptor subtype selectivity. Different VPAC receptor agonists and antagonists have been developed over the years, however, only a few of them have all these characteristics and are broadly recognized by the scientific community. Thus far, there are two selective agonists for the VPAC1 receptor, $\left[\right.$ Ala $\left.^{11,22,28}\right]$ VIP (32) and $\left[\mathrm{Lys}^{15}, \operatorname{Arg}^{16}\right.$, Leu $\left.^{27}\right]$ VIP (1-7)/CRF $(8-17,24-33)$. A molecule derived from this agonist, $\mathrm{AcHis}^{1}$ $\left[\mathrm{DPhe}^{2}, \mathrm{Lys}^{15}, \mathrm{Arg}^{16}{ }^{16} \mathrm{Leu}^{27}\right.$ ]VIP (1-7)/CRF (8-17, 24-33), also called PG97-269, is currently the only selective antagonist for the VPAC1 receptor (34). Ro 25-1553 and Ro 25-1392 are the only selective agonists for the VPAC2 receptor described thus far $(35,36)$. An artificial VPAC2 receptor antagonist, the cyclic peptide VIPpep-3 (Ac-CPPYLPRLCTLLLRS-OH), which has the characteristics abovementioned for a good antagonist, has recently been described (37). Studies with VPAC1 and VPAC2 chimeric receptors have shown that different agonists or selective antagonists of these receptors require interactions with different domains in the receptors to generate their selectivity (38). For example, the $\mathrm{N}$-terminal extracellular domain is responsible for the selectivity of the PG97-269 VPAC1 antagonist, whereas the selective recognition of the VPAC1 agonist, [Lys ${ }^{15}$, $\operatorname{Arg}^{16}$, Leu $^{27}$ JVIP (1-7)/CRF (8-17, 24-33), is supported by a large receptor area, namely the $\mathrm{N}$-terminal domain, the first extracellular loop, and additional determinants in the distal part of this receptor (39). Moreover, new delivery strategies are being developed to improve the potency, selectivity and pharmacokinetics of VIP. The most striking development is nanotechnology, which provides a VIP-controlled drug delivery, avoiding the peptide breakdown by proteases and digestive acids before it reaches its target (40).

In light of this, we could consider that the traditional point of view, in which cell surface GPCRs are the only targets for therapeutic beneficial drugs or for studying their signaling pathways and functional consequences, is incomplete. Upon activation at the cell surface, many GPCRs with their agonists traffic through intracellular compartments like endosomes or the nucleus, where they can continue to signal. VPAC receptors are no different from other GPCRs, and thus, it is important to define what functions are exerted by these receptors, depending on their location in the cell. It is necessary to develop better techniques to reveal the molecular details of signaling by unmodified VPAC receptors and their spectrum of signaling and regulatory partners in subcellular microdomains of functionally relevant cells in real time (41). Approaches such as cryoelectron tomography, which can provide structural information about protein signaling complexes in intact cells, or GPCR ascorbate peroxidase (GPCRAPEX), which can be used for the identification of proteins that are closely associated with GPCRs by mass spectrometry, will be very useful (41). In addition, it is necessary to develop VPAC receptor agonists or antagonists that specifically target intracellular VPAC receptors to achieve more specific modulation of their physiological responses.

\section{VIP/VPAC AXIS IN ANIMAL MODELS OF RHEUMATOID ARTHRITIS}

Collagen-induced arthritis (CIA) is a model that can be induced in mice, rats or primates. It shares different features with RA, as immunization of animals with type II collagen leads to a chronic, destructive polyarthritis (42) and thus, this model is widely used to study the mechanisms involved in this disease. In 2001, Delgado and colleagues described for the first time how VIP treatment of CIA mice improves the progression of the disease, reducing the incidence and severity of arthritis and avoiding joint swelling and destruction of cartilage and bone (43). Mice treated with VIP daily were best protected from the disease, although a single administration at the onset of CIA was enough to decrease the severity. The mechanisms underlying the improvement of the disease are immunomodulatory as VIP regulates $\mathrm{T}$ helper (Th1/Th2 balance, diminishing Th1 and augmenting Th2 cytokines and cells, and it decreases the $\mathrm{T}$ helper: $\mathrm{T}$ suppressor ratio. Moreover, VIP also affects the inflammatory components of the disease, as VIP treatment downregulates numerous proinflammatory factors, as well as several chemokines while it increases anti-inflammatory cytokines. Furthermore, VIP also affects the inflammatory components of the disease, as VIP treatment downregulates numerous pro-inflammatory factors, as well as several chemokines while it increases anti-inflammatory cytokines. Moreover, VIP decreases the expression and activity of matrix metalloproteinases, therefore inhibiting cartilage destruction and bone erosion. The main receptor involved in VIP effects on arthritis is VPAC1, as demonstrated by the use of specific agonists in arthritic mice (43). VIP inhibits the LPSinduced release of cytokines involved in the production of proinflammatory mediators in CIA rats, and reduces the TNF $\alpha$ induced proliferation of synovial cells by downregulating the enhanced expression and activity of NFКB transcription factor. Moreover, the use of a VPAC antagonist counteracts the effect of VIP (44).

Some studies have corroborated the anti-inflammatory role of VIP in the CIA mice model, deepening our understanding of the 
pathways, receptors, and cell types involved. For instance, VIP is able to diminish the expression of inflammatory mediators and cytokines related to bone destruction, while enhancing the expression of those related to bone protection by means of $\mathrm{NF} \kappa \mathrm{B}$ and Jun N-terminal kinase pathways (45). Moreover, a selective VPAC1 agonist is able to reduce the chronic inflammation of synovial tissue, the expression of inflammatory cytokines and chemokines, cartilage destruction, and bone erosion, whereas the selective VPAC2 agonist is not (46). Synovial cells are the major producers of innate immune inflammatory mediators, but dendritic cells (DCs) are also able to produce these mediators, driving, at least in part, inflammation in RA. In this regard, a recent study showed that DCs differentiated from monocytes in the presence of VIP are tolerogenic DCs which, when administrated to CIA mice, reduce the arthritic scores (47).

Studies in the CIA rat model demonstrate that VIP reduces the severity of the disease by regulating the balance of Th1/Th2, enhancing regulatory $\mathrm{T}$ cells (Treg) and reducing Th17 cells, modulating the mediators of bone erosion $(48,49)$. Moreover, the expression of the three VIP receptors on osteoclasts is downregulated with the onset of the disease in this model, and VIP diminishes the activity of these bone-related cells (50). VPAC1 expression is shown to be downregulated in synovial tissue of CIA rats and is enhanced by electroacupuncture treatment while VPAC2 remains the same (51). In the most recent paper published thus far, the authors hypothesized that VIP downregulates the CIA rat model by virtue of the enrichment of regulatory monocytes (52).

Given the short half-life of this peptide, some attempts have been made to achieve better targeting to inflammation sites of VIP, with lower doses required, such as viral and non-viral vectors to deliver VIP by gene therapy, the generation of latent forms of this peptide by fusion to latency-associated peptides, or the administration of VIP inside stabilized micelles. All of these innovative forms of delivery have been assayed in the CIA model of rheumatoid arthritis $(18,53,54)$.

Other models that have been very useful in the study of the VIP/VPAC axis are the genetically modified mice, knockout mice, which have served to better understand the involvement of endogenously produced VIP. Mice lacking VIP gene by homologous recombination, were able to survive to weaning, despite the wide distribution of this peptide in the organism, but with important alterations in circadian rhythms (55). Moreover, VIP KO mice exhibit changes in reproductive function, behavior, feeding, metabolism, bladder function and gastrointestinal tract as it has been recently reviewed (56). PACAP, VPAC1, VPAC2, and PAC1 knockout mice have also been developed which has served to identify the involvement of these receptors in different physiological processes (56). All these KO models have shown normal basal immune characteristics, although when subjected to immune diseases models, they exhibited impaired immune responses. For instance, VIP KO developed more severe dinitrobenzene sulfonic acid (DNBS)-induced colitis, exacerbated inflammatory asthma and enhancement of innate and adaptive immune responses in a model of viral infection than wild-type mice. However, opposing effects in several inflammatory/autoimmune models developed in VIP KO mice such as LPS-induced endotoxemia, TNBS- and DSS induced-colitis and experimental autoimmune encephalomyelitis (EAE), a model for multiple sclerosis, have been reported (57-59). To date, there is no clear explanation for these results and different hypotheses have emerged that should be verified. Among others, it has been proposed that under some conditions the involvement of VIP could be essential for the whole expansion of immune responses. The existence of compensatory mechanisms by PACAP and the involvement of microbiota have also been suggested (56). VPAC1 KO mice showed diminished inflammatory responses in DNBS-induced colitis and a resistant phenotype to EAE. Besides, VPAC2 KO mice were subjected to skin immediate-type (ITH) and delayedtype (DTH) hypersensitivity models and showed enhanced DTH with augmented Th1 but reduced Th2 cytokine generation and reduced ITH, suggesting a protective role of this receptor against Th1-driven diseases, furthermore, VPAC2 KO mice exhibited exacerbated EAE compared to wild-type mice (56). Unfortunately, as far as we know, there are no studies carried out with the CIA model in mice deficient of VIP, which could serve to corroborate the data described above.

\section{VPAC RECEPTORS SIGNALING CONTROL IMMUNE RESPONSE IN HEALTHY AND RA PATIENTS}

Immune dysregulation is at the core of RA pathogenesis, implying disordered immune responses at both systemic and local levels. Furthermore, joints affected by RA characteristically exhibit an altered hyper-activation state of the synovial stromal tissue, which also plays a critical role in the joint pathology. During RA progression, the synovial lining layer expands up to 10-12 cells in thickness, comprised of both SF and macrophages, and the sublining is infiltrated by adaptive and innate immune cells, including $\mathrm{B}$ and $\mathrm{T}$ lymphocytes as well as inflammatory monocytes, which will differentiate into macrophages (60).

\section{Synovial Fibroblasts}

Joint resident RA synovial fibroblasts (RASF) are mesenchymal stromal cells with immunomodulatory capabilities that secrete cytokines, chemokines and matrix damaging enzymes, actively contributing to synovitis, and ultimately, to cartilage/bone destruction (61, 62). RASF assume an autonomous pathogenic phenotype characterized by the capacity for hyperproliferation and migration, which contributes to the synovium hyperplasia and to the spread of the disease to unaffected joints (63). The pathogenic behavior of RASF is activated and enhanced in response to multiple pathways, including pro-inflammatory mediators and Toll-like receptor (TLR) ligands present in the RA synovium (64).

VIP anti-inflammatory signaling is functional in RASF, decreasing the production of pro-inflammatory cytokines and chemokines (65), also showing immunomodulatory effects on TLR2 and TLR4 through a negative regulation of their expression and function (66). Moreover, VIP exerts an inhibitory action over several RNA sensors involved in the activation of RASF, including 
TLR3, TLR7 and helicases RIG-I and MDA-5 (67). VIP is also able to counterbalance the enhancing effect of pro-inflammatory molecules on the expression of IL-17 receptors by RASF and on their production of IL-12 and IL-23 cytokines, which are involved in the facilitation of Th1 and Th17 differentiation, respectively (68).

Effects of VIP on RASF are mediated by its receptors, VPAC1 and VPAC2, which exhibit a differential expression pattern when compared to osteoarthritis (OA) SF. VPAC2 is the dominant receptor in RASF whereas VPAC1 is preferentially detected in OASF, with no presence of PAC1 receptor in either type of SF $(4,69)$. It is worth noting that TNF $\alpha$-treated OASF adopt a pattern of expression for VPAC receptors equivalent to RA, suggesting a modulatory effect of the pro-inflammatory synovial milieu on the VPAC system. The functional activity of VPAC receptors in OA and RASF is coupled to adenylate cyclase (AC), and specific agonists for each receptor subtype are equivalent to VIP in inducing an increase in intracellular cAMP levels by activating the dominant receptor, VPAC1 and VPAC2, respectively. Specifically, the VPAC2-specifc agonist reproduces the inhibitory effects of VIP on pro-inflammatory CXCL8, IL6 and CCL2 production by RASF (4). Therefore, VPAC2 is the receptor mediating the immunomodulatory effects of VIP on RASF through the activation of the AC pathway.

\section{Monocytes/Macrophages}

RA synovial macrophages are considered central effectors in the progression of joint degeneration, by secreting several proinflammatory cytokines and joint-damaging mediators (70). In fact, pathological contribution of SF to RA progression is directly linked to both resident and monocyte-derived infiltrating macrophages $(71,72)$. The number of synovial sublining macrophages is correlated with the degree of joint erosion and disease activity in RA patients (73). Specifically, RA synovial macrophages exhibit a transcriptomic and protein profile that is similar to that of macrophages polarized in vitro by GM-CSF (GM-MØ), also known as M1. GM-M $\varnothing$ are characterized by the expression and secretion of pro-inflammatory factors in contrast to macrophages polarized by M-CSF (M$\mathrm{M} \varnothing)$, also known as M2, that display an anti-inflammatory profile (74).

Most studies demonstrate that VPAC1 is constitutively expressed at higher levels than VPAC2 in resting human monocytes/macrophages, whereas VPAC2 expression is induced by immune stimulation (75-78). Other authors have described the expression of PAC1 and the absence of VPAC2 in these cells, probably as a result of the different methods used (77-79). More recently, the analysis of VPAC receptors expression during the time course of the in vitro polarization of monocytes toward GM-M $\varnothing$ or $\mathrm{M}-\mathrm{M} \varnothing$ showed a progressive down-regulation of transcripts for VPAC1 and VPAC2, detecting higher levels for both receptors in GM-MØ at the end of the process. Likewise, RA synovial macrophages, according to their GM-CSFlike polarization state, exhibited a higher expression of VPAC1 and VPAC2 compared to macrophages from a non-inflamed synovium (78).
Regarding the functional activity of VPAC receptors in human monocytes, inhibitory signals of the VPAC2-specific agonist on LPS-induced synthesis of TNF $\alpha$ and IL-12 have been described (75). Likewise, VIP is able to reduce the synthesis of TNF $\alpha$, IL-6, and IL-12 by in vitro-generated GMMØ stimulated with LPS. In this regard, specific agonists for VPAC receptors induce an increase in intracellular cAMP levels in GM-MØ, with the VPAC1 agonist reaching levels comparable to those induced by VIP. Moreover, the presence of either VPAC1 or VPAC2 agonists during the GM-CSFdriven in vitro polarization impairs the expression of GM-M $\varnothing$ specific gene markers and up-regulates some genes linked to $\mathrm{M}-\mathrm{M} \emptyset$, changing the macrophage profile to a less-damaging phenotype (78).

\section{Helper T Cells (Th) Cells}

Naïve CD4+ Th cells can differentiate into several effector subsets called Th1, Th2, Th17, Th9, Th22 or follicular helper $\mathrm{T}$ (Tfh), and Treg. The differentiation of these subsets is coordinated by complex regulatory networks that allow for shared transcriptional programs and plasticity across $\mathrm{T}$ cell subsets $(80,81)$. Effector Th cells (Th1, Th2, Th17, Th9, Th22, Tfh) are important for protective immunity and Treg are responsible for the tolerance of the immune system, however some of these subsets have been related to a greater or lesser extent with malfunctions of the immune system, specifically autoimmune diseases, like RA $(82,83)$. Before the discovery of Th17, RA was thought to be due to an increase in the Th1 subset and a loss of tolerance, Treg. Nowadays, Th17 cells have acquired a key role in the pathogenesis of RA (82-85). This subset is heterogenic and can show a pathogenic or nonpathogenic profile, depending on the cytokine balance present in the microenvironment during its differentiation/activation. In addition, Th17 cells are the most plastic subset of all the others. Pathogenic Th17 cells are directly involved in RA and are able to change their lineage commitment, shifting to Th1 cells (termed "non-classical Th1" cells or "Th17/1" cells), which are reported to be more pathogenic than Th17 cells per se in RA (84-87).

As stated above, in the animal model of RA, the CIA model, VIP is able to rebalance Th1/Th2 subsets in the immune system, decreasing Th1 cells and increasing Th2 cells, and to downregulate Th17 responses. Furthermore, VIP also expands Treg cells in the periphery in this animal model, which inhibits autoreactive $\mathrm{T}$ cell activation/expansion, for example increasing Treg/Th17 balance $(43,48,88,89)$. In peripheral blood lymphocytes of RA patients cultured ex vivo, VIP favors the Th2/Treg profile (90). In addition, VIP reduces the Th17 and Th17/1 pathogen profile of memory Th cells of early RA patients activated/expanded ex vivo $(89,91)$. Even when memory Th cells from early RA patients are polarized in vitro to a non-pathogenic Th17 profile in the presence of TGF $\beta$, they maintain a pathogenic profile (92). However, the presence of VIP during this Th17 polarization, increases their Treg/Th17 profile, characteristic of non-pathogenic Th17 cells, and decreases the Th17/Th1 profile, characteristic of the pathogenic phenotype $(89,92)$. 
Th cell activation induces changes in the expression of VPAC receptors and their cellular location $(17,79,86,89,91-93)$. Th lymphocytes from mouse and human express both VPAC1 and VPAC2 receptors and their mRNA expression patterns change between Th cells from mouse, healthy donors and patients with early RA. Activation of Th cells results in a loss of VPAC1 mRNA expression, the range of expression of VPAC1 is between 11- and 61-fold higher in resting Th cells than activated cells, however no changes at the protein level are detected in Th cells from healthy donors or from early RA patients $(17,79,89,91)$. The VPAC2 mRNA and protein expression is up-regulated after in vitro activation, whereas low levels of VPAC2 are present in resting Th cells, the range of expression is between 2- and 5fold higher in activated Th cells than resting cells $(17,79,89)$. In relation to their cellular location changes, in resting Th cells, VPAC1 is found both on the cell surface and intracellularly, whereas when these cells are activated, this receptor is found exclusively inside the cell. This change in the receptor cellular location is not observed for VPAC2 since it is always on the cellular surface, regardless of the activation state of Th cells (17). As early as Goetzl (94) hypothesized that VPAC receptors constitute a dynamic system for signaling in $\mathrm{T}$ cells, predicting that responses in the plasma membrane location would have a fast onset and brief duration, whereas receptors in the nuclear membrane would have responses with slow onset, sustained in time (94). This fact is reflected in the signaling pathways that these receptors trigger, as they signal through a PKAdependent pathway in resting or activated Th cells, and also by a PKA-independent pathway in activated cells (17). In this way, both receptors exhibit a potent immunomodulatory capacity by controlling the pathogenic profile and the activation markers of Th cells.

As it is above mentioned, the implication of Th1 cells was initially ascribed to RA, however the discovery of the Th17 subset indicated a central role for these cells in this pathology. VIP is able to modulate the differentiation and polarization of these subsets in cells from RA patients. Thus, changes in the pattern expression of VPAC are also important for the pathology. In this context, the differentiation/polarization of Th cells also induces changes in the expression of VPAC receptors; for example, the differentiation/polarization toward Th17 profile induces an increase in the VPAC2/VPAC1 ratio, for example, 18-fold in Th17-differentiated cells from naïve Th cells $(86,92)$. During the process of differentiation toward a non-pathogenic Th17 profile, VPAC receptors have shown different roles in regulating the production of inflammatory mediators (86).

When VPAC receptor expression in Th cells from healthy donors is compared with that of patients with early RA, the VPAC2/VPAC1 ratio is 2.8-fold higher in cells from early RA patients $(17,91,92)$. These data perfectly correlate with the VPAC receptor expression in PBMCs from early RA patients as we described. Briefly, there is a loss of VPAC1 mRNA expression and an increase in VPAC2 expression in these patients (23). We can conclude that VIP is a beneficial modulator that counterbalances the different Th subsets and underscores the importance of VPAC expression in RA.

\section{CLINICAL SIGNIFICANCE OF VIP AND VPAC RECEPTORS}

\section{Could VIP Be Useful as a Drug?}

The knowledge generated in animal models and in human $e x$ vivo studies related to VIP and its signaling pathways could be translated to clinical reality as two potential tools: as a therapeutic agent and as a biomarker in inflammatory/autoimmune diseases.

Although RA disease has no cure, in the last two decades, rheumatologists through an early diagnosis and rapid initiation of an effective therapy are achieving disease remission or at least significantly reducing the activity of the disease.

The present management strategy of RA, accepted by ACR, EULAR, and the Asia Pacific League of Associations for Rheumatology, is the "treat to target" method, which is based on the strict control of the disease activity and the modification of the treatment if the goal is not achieved (95-97).

The currently used therapeutic strategies include the nonsteroidal anti-inflammatory drugs (NSAIDs) as symptomatic agents, glucocorticoids used for prevention of joint destruction, and the disease-modifying anti-rheumatic drugs (DMARDs). DMARDs comprise both synthetic (conventional drugs such as methotrexate and targeted synthetic drugs such as JAK inhibitors) and biological agents designed for the specific inhibition of molecules of the immune system, such as TNF, IL6, IL-6 receptor, CD80-CD86, and CD20. The best results are being achieved with the combined therapy of biological agents and methotrexate. This approach to RA remission produces an improvement of the physical function and prevention of evolution of joint damage. Nevertheless, many patients fail to decrease disease activity and advances in the development of new or complementary therapies are still required (98).

An efficient translation of preclinical studies to the field of health for the use of VIP as a therapeutic agent faces two important challenges. On the one hand, it has low metabolic stability with a short in vivo half-life, due to its degradation by proteases, by spontaneous hydrolysis or by catalytic antibodies (54). On the other hand, the systemic administration of VIP can cause side effects due to the cross-interactions of binding to three GPCRs, its functional pleiotropism and its ubiquity. Severe decreases of the blood pressure, and alterations in the cardiovascular and gastrointestinal system such as the watery diarrhea syndrome $(99,100)$, have been documented. Thus, VIP-mediated therapeutic intervention in RA management must include the design of distribution systems directed against specific targets and the protection of the peptide against its degradation. Unfortunately, none of the strategies designed, such as the use of VIP analogs or the application of protease inhibitors, have rendered effects for use in systemic therapy.

With this background, the field of nanoparticle engineering has been developed over the last few years, generating attractive data, although not yet sufficient, for clinical application (40). Two strategies have been developed with VIP-based nanoparticles: (a) to act itself as a drug by means of encapsulation or by its attachment to the surface of the nanoparticle; or (b) to serve as a vehicle for another compound to a precise location. In this second strategy, phospholipid nanomicelles spliced with VIP 
target acting as carriers for water-insoluble anticancer drugs has been used in breast cancer (101). The same approach has been used in RA in a study testing a new indication for the anti-cancer drug camptothecin a Topoisomerase I inhibitor. Camptothecin sterically stabilized micelles conjugated with VIP (CPT-SSM-VIP) has been designed to be delivered in specific cell types, such as synoviocites, T-cells and macrophages, where VPAC2 are over-expressed. This approach of actively targeting long circulating micelles to the effector cells in RA joints improved the efficacy of the drug and reduced systemic toxicity. They reported that a single, subcutaneous injection of low-dose camptothecin preparation alleviated joint inflammation in the CIA model (102).

Regarding the strategy of nanoparticles developed for VIP as a drug, recently the beneficial effects in the CIA murine model have been reported by targeting low doses of VIP self-associated with sterically stabilized micelles (SSMs) $[(18,19)$; Figure 1]. This spontaneous interaction of VIP with SSM protects the peptide from enzymatic degradation or inactivation in biological fluids and prolongs circulation half-life. The small size of the VIP particles $(\sim 15 \mathrm{~nm})$ prevents the nanoparticle from extravasating through undamaged blood vessel walls abolishing vasorelaxation and also carrying the particles to the sites with "permeable" vasculature, such as inflamed tissues. While the authors suggest that the components of VIP-SSM formulation have been used for humans in marketed pharmaceutical products such as InvicorpR and DoxilR, there are still problems to be solved regarding their biodistribution, not only in the joints but also in the kidney and liver (18).

In a recent study, this strategy confirmed that VIP-SSM prevented and ameliorated severe inflammation related to DSS-induced colitis, in a murine model of inflammatory bowel disease. The treatment reversed the augmented proinflammatory cytokine expression (IL-1 $\beta$, CXCL1, CXCL2, and CCL3), injured distal colonic histology, and reduced tight junction (occludin expression) and ion transporter protein expression associated with severe DSS colitis [(20); Figure 1].

The negative side of the current systemic RA treatments, previously described, is the appearance of side effects. These are generated by the toxicity associated with long-term treatments and large doses that these drugs induce. To evade the off-target toxicity of these drugs, a potential solution is the development of joint-targeting drug delivery. The VIP-based strategy for targeted RA still requires more research, and the resolution of different problems, being one of them, to guarantee their arrival exclusively to the joint.

\section{Tracing the Potential of the VIP/VPAC Receptors Axis as Biomarker}

The early recognition and treatment of RA is hampered by its heterogeneous nature. Current strategies for the management of RA focus on identification and intervention in the "window of opportunity," the initial period of the disease in which joint damage can be avoided through early and continuous therapy to slow or stop the evolution of the disease $(21,103)$ as discussed above. Thus, new challenges emerge in the search of prognostic biomarkers to guide personalized treatment decisions.
Given these concerns, we have recently described the utility of measuring VIP as a clinical biomarker in patients with early arthritis (EA) (104). We demonstrate an association between VIP serum levels and genetic variants in the VIP gene and describe certain combinations of genotypes of these variants associated with a greater intensity of treatment in our patients $(21,23)$. These results highlight the relevance of the detection of VIP genetic variants that allows the stratification of patients as a complementary tool for supporting therapeutic decisions.

New evidence underscores the importance of the VIP/receptors axis through the association of expression levels of VPAC receptors with the clinical status of EA patients (22). In a population of early arthritis EA patients, we evaluated the expression of VPAC1 and VPAC2 in PBMCs during the clinical follow-up (22). We reported that the expression of VPAC1 increased significantly reaching the highest values after 2 years of follow-up, whereas VPAC2 expression decreased. Thus, we described an inverse correlation between the expressions of both receptors during the course of EA suggesting a possible dynamic regulation in the different stages of the disease probably as a compensatory mechanism (22).

The assessment of the activity of RA by several variables is of crucial importance in daily clinical practice with the aim of reducing inflammation and achieving remission. Elevated levels of IL- 6 in the serum of patients are considered a marker of inflammation correlating directly to the clinical activity of the disease and to joint destruction $(105,106)$. Interestingly, a negative correlation has been described between the levels of VPAC1 and IL-6, parallel to the positive association between the levels of this cytokine and the VPAC2 receptor (22). This result points to the role of the low level of expression of VPAC1 as a marker of a more intense inflammatory process.

What is truly remarkable, however, is the relationship between VPAC1 levels and the activity of the disease measured by the disease activity score (DAS), DAS 28 index. Thus, when we clustered EA patients into 3 sub-groups considering their DAS28 levels (remission-low, moderate, and high disease activity), we found that patients with moderate/high activity of the disease show the lowest levels of VPAC1, while patients in remission have higher levels of this receptor. In addition, the expression of VPAC1 makes it possible to distinguish groups of patients with different degrees of disease activity that could serve as an indicator of disease activity in RA (22).

In light of the above, the evaluation of the global activity of the disease by the patient has been gaining relevance in the determination of the outcome of RA showing a high predictive value $(107,108)$ and allowing pathways to improvement, not only in terms of the traditional objectives of decreased activity but also in terms of patient satisfaction (109). In this context, it has been demonstrated that lower levels of VPAC1 expression are associated with patient-reported impairment correlating better than other serum biomarkers of activity used in clinical practice, such as the erythrocyte sedimentation rate [(22); Figure 1].

The American College of Rheumatology/European League against Rheumatism (110), the European League against Rheumatism (111) and the international working group to address the objectives (112), recommend frequent evaluation of disease activity in order to reduce, or better 
eliminate, inflammation (113). Therefore, the identification of new biological markers, which reflect the underlying pathophysiological processes associated with the clinical activity of RA, are the target of numerous investigations.

In this sense and given the ability of VIP to regulate the intensity of the inflammatory process and the immune response, the expression of VPAC1 in RA, associated with the activity of the disease, would reflect the patient's clinical status and complement other serum biomarkers of activity used, such as ESR and Creactive protein (CRP) (114) which are biased by factors such as the gender and the disease duration (115).

In summary, we can conclude that the VIP/VPAC axis represents a promising biomarker in RA because it could allow patients to be stratified with the purpose of guiding personalized treatment decisions.

\section{CONCLUDING REMARKS}

The experimental data explained above demonstrate the VIP/VPAC receptor axis as an important endogenous mediator involved in anti-inflammatory and autoimmunity responses in RA. In recent years, sufficient information has been generated related to the VIP/VPAC receptor axis to yield an effective translation of these preclinical studies. The research area that seems most advanced for clinical application is its role as a biomarker. Important advances are being made toward obtaining the means to ensure that the determination of biomarkers allows an accurate prognosis of the onset as well as the valuation of severity of RA. According to the information reported, it may be

\section{REFERENCES}

1. Schaible HG. Nociceptive neurons detect cytokines in arthritis. Arthritis Res Ther. (2014) 16:470. doi: 10.1186/s13075-014-0470-8

2. Gomariz RP, Martinez C, Abad C, Leceta J, Delgado M. Immunology of VIP: a review and therapeutical perspectives. Curr Pharm Des. (2001) 7:89-111. doi: 10.2174/1381612013398374

3. Gomariz RP, Juarranz Y, Abad C, Arranz A, Leceta J, Martinez C. VIP-PACAP system in immunity: new insights for multitarget therapy. Ann N Y Acad Sci. (2006) 1070:51-74. doi: 10.1196/annals.1317.031

4. Juarranz Y, Gutierrez-Canas I, Santiago B, Carrion M, Pablos JL, Gomariz RP. Differential expression of vasoactive intestinal peptide and its functional receptors in human osteoarthritic and rheumatoid synovial fibroblasts. Arthritis Rheum. (2008) 58:1086-95. doi: 10.1002/art.23403

5. Gomariz RP, Gutierrez-Canas I, Arranz A, Carrion M, Juarranz Y, Leceta J, et al. Peptides targeting Toll-like receptor signalling pathways for novel immune therapeutics. Curr Pharm Des. (2010) 16:1063-80. doi: 10.2174/138161210790 963841

6. Couvineau A, Laburthe M. VPAC receptors: structure, molecular pharmacology and interaction with accessory proteins. Br J Pharmacol. (2012) 166:42-50. doi: 10.1111/j.1476-5381.2011.01676.x

7. Couvineau A, Laburthe M. The family B1 GPCR: structural aspects and interaction with accessory proteins. Curr Drug Targets. (2012) 13:103-15. doi: 10.2174/138945012798868434

8. Dickson L, Finlayson K. VPAC and PAC receptors: from ligands to function. Pharmacol Ther. (2009) 121:294-316. doi: 10.1016/j.pharmthera.2008. 11.006

9. Harikumar KG, Morfis MM, Lisenbee CS, Sexton PM, Miller LJ. Constitutive formation of oligomeric complexes between family B G protein-coupled that in this scenario, the VIP/VPAC axis occupies an important place as a biomarker of this disease. However, for its clinical application to become a reality, more research is needed. The involvement of genetic, epigenetic and miRNAs in the expression of VPAC receptors, and validation in several cohorts of patients, among other issues, are important challenges that must be addressed in future research.

\section{AUTHOR CONTRIBUTIONS}

RG, YJ, CM, MC, IG-C, IG-A and AL wrote the manuscript. SP-G and RV-R performed the figures. RG coordinated the manuscript. SP-G and RV-R coordinated the bibliography and the format of the manuscript.

\section{FUNDING}

This work was supported by the Fondo de Investigación Sanitaria, Instituto de Salud Carlos III (Grants Nos. PI14/ 00477, PI17/00027, RD16/0012/0008, and RD16/0012/0011) and by the Ministerio de Economía y Competitividad (RTC2015-3562-1), cofinanced by Fondo Europeo de Desarrollo Regional (FEDER).

\section{ACKNOWLEDGMENTS}

We are grateful to all patients and the collaborating clinicians for their participation in this study. We are also grateful to Sarah Young for her contribution to English manuscript editing.

vasoactive intestinal polypeptide and secretin receptors. Mol Pharmacol. (2006) 69:363-73. doi: 10.1124/mol.105.015776

10. Langer I. Mechanisms involved in VPAC receptors activation and regulation: lessons from pharmacological and mutagenesis studies. Front Endocrinol. (2012) 3:129. doi: 10.3389/fendo.2012.00129

11. Solano RM, Langer I, Perret J, Vertongen P, Juarranz MG, Robberecht P, et al. Two basic residues of the h-VPAC1 receptor second transmembrane helix are essential for ligand binding and signal transduction. J Biol Chem. (2001) 276:1084-8. doi: 10.1074/jbc.M007696200

12. Ceraudo E, Murail S, Tan YV, Lacapere JJ, Neumann JM, Couvineau A, et al. The vasoactive intestinal peptide (VIP) alpha-Helix up to $\mathrm{C}$ terminus interacts with the $\mathrm{N}$-terminal ectodomain of the human VIP/Pituitary adenylate cyclase-activating peptide 1 receptor: photoaffinity, molecular modeling, and dynamics. Mol Endocrinol. (2008) 22:147-55. doi: 10.1210/me.2007-0361

13. Christopoulos A, Christopoulos G, Morfis M, Udawela M, Laburthe M, Couvineau A, et al. Novel receptor partners and function of receptor activity-modifying proteins. J Biol Chem. (2003) 278:3293-7. doi: $10.1074 /$ jbc.C200629200

14. Wootten D, Lindmark H, Kadmiel M, Willcockson H, Caron KM, Barwell J, et al. Receptor activity modifying proteins (RAMPs) interact with the VPAC2 receptor and CRF1 receptors and modulate their function. Br J Pharmacol. (2013) 168:822-34. doi: 10.1111/j.1476-5381.2012. 02202.x

15. Rueda CM, Jackson CM, Chougnet CA. Regulatory T-cell-mediated suppression of conventional T-cells and dendritic cells by different cAMP intracellular pathways. Front Immunol. (2016) 7:216. doi: $10.3389 /$ fimmu.2016.00216

16. Gutierrez-Canas I, Juarranz MG, Collado B, Rodriguez-Henche N, Chiloeches A, Prieto JC, et al. Vasoactive intestinal peptide induces 
neuroendocrine differentiation in the LNCaP prostate cancer cell line through PKA, ERK, and PI3K. Prostate. (2005) 63:44-55. doi: $10.1002 /$ pros. 20173

17. Villanueva-Romero R, Gutierrez-Canas I, Carrion M, Gonzalez-Alvaro I, Rodriguez-Frade JM, Mellado M, et al. Activation of Th lymphocytes alters pattern expression and cellular location of VIP receptors in healthy donors and early arthritis patients. Sci Rep. (2019) 9:7383. doi: 10.1038/s41598-019-43717-2

18. Sethi V, Rubinstein I, Kuzmis A, Kastrissios H, Artwohl J, Onyuksel H. Novel, biocompatible, and disease modifying VIP nanomedicine for rheumatoid arthritis. Mol Pharm. (2013) 10:728-38. doi: 10.1021/mp300539f

19. Feng X, Chen Y. Drug delivery targets and systems for targeted treatment of rheumatoid arthritis. J Drug Target. (2018) 26:845-57. doi: 10.1080/1061186X.2018.14 33680

20. Jayawardena D, Anbazhagan AN, Guzman G, Dudeja PK, Onyuksel $\mathrm{H}$. Vasoactive intestinal peptide nanomedicine for the management of inflammatory bowel disease. Mol Pharm. (2017) 14:3698-708. doi: 10.1021/acs.molpharmaceut.7b00452

21. Gonzalez-Alvaro I, Ortiz AM, Seoane IV, Garcia-Vicuna R, Martinez C, Gomariz RP. Biomarkers predicting a need for intensive treatment in patients with early arthritis. Curr Pharm Des. (2015) 21:170-81. doi: 10.2174/1381612820666140825123104

22. Seoane IV, Ortiz AM, Piris L, Lamana A, Juarranz Y, Garcia-Vicuna R, et al. Clinical Relevance of VPAC1 receptor expression in early arthritis: association with IL-6 and disease activity. PLoS ONE. (2016) 11:e0149141. doi: 10.1371/journal.pone.0149141

23. Seoane IV, Martinez C, Garcia-Vicuna R, Ortiz AM, Juarranz Y, Talayero VC, et al. Vasoactive intestinal peptide gene polymorphisms, associated with its serum levels, predict treatment requirements in early rheumatoid arthritis. Sci Rep. (2018) 8:2035. doi: 10.1038/s41598-018-20400-6

24. Langer I, Leroy K, Gaspard N, Brion JP, Robberecht P. Cell surface targeting of VPAC1 receptors: evidence for implication of a quality control system and the proteasome. Biochim Biophys Acta. (2008) 1783:1663-72. doi: 10.1016/j.bbamcr.2008.03.013

25. Shetzline MA, Walker JK, Valenzano KJ, Premont RT. Vasoactive intestinal polypeptide type-1 receptor regulation. Desensitization, phosphorylation, and sequestration. J Biol Chem. (2002) 277:25519-26. doi: 10.1074/jbc.M201815200

26. Mahavadi S, Bhattacharya S, Kim J, Fayed S, Al-Shboul O, Grider JR, et al. Caveolae-dependent internalization and homologous desensitization of VIP/PACAP receptor, VPAC(2), in gastrointestinal smooth muscle. Peptides. (2013) 43:137-45. doi: 10.1016/j.peptides.2013.03.008

27. Magalhaes AC, Dunn H, Ferguson SS. Regulation of GPCR activity, trafficking and localization by GPCR-interacting proteins. $\mathrm{Br} J$ Pharmacol. (2012) 165:1717-36. doi: 10.1111/j.1476-5381.2011.01552.x

28. Bhosle VK, Rivera JC, Chemtob S. New insights into mechanisms of nuclear translocation of G-protein coupled receptors. Small GTPases. (2019) 10:25463. doi: 10.1080/21541248.2017.1282402

29. Valdehita A, Bajo AM, Fernandez-Martinez AB, Arenas MI, Vacas E, Valenzuela $\mathrm{P}$, et al. Nuclear localization of vasoactive intestinal peptide (VIP) receptors in human breast cancer. Peptides. (2010) 31:2035-45. doi: 10.1016/j.peptides.2010.07.024

30. Barbarin A, Seite P, Godet J, Bensalma S, Muller JM, Chadeneau C. Atypical nuclear localization of VIP receptors in glioma cell lines and patients. Biochem Biophys Res Commun. (2014) 454:524-30. doi: 10.1016/j.bbrc.2014.10.113

31. Yu R, Liu H, Peng X, Cui Y, Song S, Wang L, et al. The palmitoylation of the $\mathrm{N}$-terminal extracellular Cys37 mediates the nuclear translocation of VPAC1 contributing to its anti-apoptotic activity. Oncotarget. (2017) 8:42728-41. doi: 10.18632/oncotarget.17449

32. Nicole P, Lins L, Rouyer-Fessard C, Drouot C, Fulcrand P, Thomas A, et al. Identification of key residues for interaction of vasoactive intestinal peptide with human VPAC1 and VPAC2 receptors and development of a highly selective VPAC1 receptor agonist. Alanine scanning and molecular modeling of the peptide. J Biol Chem. (2000) 275:24003-12. doi: $10.1074 /$ jbc.M002325200
33. Gourlet P, Vandermeers A, Vertongen P, Rathe J, De Neef P, Cnudde J, et al. Development of high affinity selective VIP1 receptor agonists. Peptides. (1997) 18:1539-45. doi: 10.1016/S0196-9781(97) 00228-3

34. Gourlet P, De Neef P, Cnudde J, Waelbroeck M, Robberecht P. In vitro properties of a high affinity selective antagonist of the VIP1 receptor. Peptides. (1997) 18:1555-60. doi: 10.1016/S0196-9781(97) 00230-1

35. Gourlet P, Vertongen P, Vandermeers A, Vandermeers-Piret MC, Rathe J, De Neef $\mathrm{P}$, et al. The long-acting vasoactive intestinal polypeptide agonist RO 25-1553 is highly selective of the VIP2 receptor subclass. Peptides. (1997) 18:403-8. doi: 10.1016/S0196-9781(96)00322-1

36. Xia M, Sreedharan SP, Bolin DR, Gaufo GO, Goetzl EJ. Novel cyclic peptide agonist of high potency and selectivity for the type II vasoactive intestinal peptide receptor. J Pharmacol Exp Ther. (1997) 281:629-33.

37. Sakamoto K, Koyama R, Kamada Y, Miwa M, Tani A. Discovery of artificial VIPR2-antagonist peptides possessing receptor- and ligand-selectivity. Biochem Biophys Res Commun. (2018) 503:1973-9. doi: 10.1016/j.bbrc.2018.07.144

38. Juarranz MG, Van Rampelbergh J, Gourlet P, De Neef P, Cnudde J, Robberecht P, et al. Vasoactive intestinal polypeptide VPAC1 and VPAC2 receptor chimeras identify domains responsible for the specificity of ligand binding and activation. Eur J Biochem. (1999) 265:449-56. doi: 10.1046/j.1432-1327.1999.00769.x

39. Juarranz MG, Van Rampelbergh J, Gourlet P, De Neef P, Cnudde J, Robberecht P, et al. Different vasoactive intestinal polypeptide receptor domains are involved in the selective recognition of two $\operatorname{VPAC}(2)$-selective ligands. Mol Pharmacol. (1999) 56:1280-7. doi: 10.1124/mol.56.6.1280

40. Klippstein R, Pozo D. Vasoactive intestinal peptide (VIP) nanoparticles for diagnostics and for controlled and targeted drug delivery. Adv Protein Chem Struct Biol. (2015) 98:145-68. doi: 10.1016/bs.apcsb.2014.11.006

41. Thomsen ARB, Jensen DD, Hicks GA, Bunnett NW. Therapeutic targeting of endosomal G-protein-coupled receptors. Trends Pharmacol Sci. (2018) 39:879-91. doi: 10.1016/j.tips.2018.08.003

42. Myers LK, Rosloniec EF, Cremer MA, Kang AH. Collagen-induced arthritis, an animal model of autoimmunity. Life Sci. (1997) 61:1861-78. doi: 10.1016/S0024-3205(97)00480-3

43. Delgado M, Abad C, Martinez C, Leceta J, Gomariz RP. Vasoactive intestinal peptide prevents experimental arthritis by downregulating both autoimmune and inflammatory components of the disease. Nat Med. (2001) 7:563-8. doi: $10.1038 / 87887$

44. Yin $\mathrm{H}$, Cheng $\mathrm{H}, \mathrm{Yu}$ M, Zhang F, Lin J, Gao Y, et al. Vasoactive intestinal peptide ameliorates synovial cell functions of collagen-induced arthritis rats by down-regulating NF-kappaB activity. Immunol Invest. (2005) 34:153-69. doi: 10.1081/IMM-55809

45. Juarranz Y, Abad C, Martinez C, Arranz A, Gutierrez-Canas I, Rosignoli F, et al. Protective effect of vasoactive intestinal peptide on bone destruction in the collagen-induced arthritis model of rheumatoid arthritis. Arthritis Res Ther. (2005) 7:R1034-45. doi: 10.1186/ar1779

46. Delgado M, Robledo G, Rueda B, Varela N, O'valle F, Hernandez-Cortes $\mathrm{P}$, et al. Genetic association of vasoactive intestinal peptide receptor with rheumatoid arthritis: altered expression and signal in immune cells. Arthritis Rheum. (2008) 58:1010-9. doi: 10.1002/art.23482

47. Wu H, Shen J, Liu L, Lu X, Xue J. Vasoactive intestinal peptideinduced tolerogenic dendritic cells attenuated arthritis in experimental collagen-induced arthritic mice. Int J Rheum Dis. (2019) 22:1255-62. doi: 10.1111/1756-185X.13578

48. Chen G, Hao J, Xi Y, Wang W, Wang Z, Li N, et al. The therapeutic effect of vasoactive intestinal peptide on experimental arthritis is associated with CD4+CD25+ T regulatory cells. Scand J Immunol. (2008) 68:572-8. doi: $10.1111 / j .1365-3083.2008 .02178 . x$

49. Deng S, Xi Y, Wang H, Hao J, Niu X, Li W, et al. Regulatory effect of vasoactive intestinal peptide on the balance of Treg and Th17 in collagen-induced arthritis. Cell Immunol. (2010) 265:105-10. doi: 10.1016/j.cellimm.2010.07.010

50. Muschter D, Schafer N, Stangl H, Straub RH, Grassel S. Sympathetic neurotransmitters modulate osteoclastogenesis and osteoclast activity in 
the context of collagen-induced arthritis. PLoS ONE. (2015) 10:e0139726. doi: 10.1371/journal.pone.0139726

51. Zhu J, Chen XY, Li LB, Yu XT, Zhou Y, Yang WJ, et al. Electroacupuncture attenuates collagen-induced arthritis in rats through vasoactive intestinal peptide signalling-dependent re-establishment of the regulatory $\mathrm{T}$ cell/T-helper 17 cell balance. Acupunct Med. (2015) 33:305-11. doi: 10.1136/acupmed-2014-010732

52. Guan L, Yu D, Wu GH, Ning HJ, He SD, Li SS, et al. Vasoactive intestinal peptide is required in the maintenance of immune regulatory competency of immune regulatory monocytes. Clin Exp Immunol. (2019) 196:276-86. doi: $10.1111 /$ cei.13259

53. Delgado M, Toscano MG, Benabdellah K, Cobo M, O’valle F, Gonzalez-Rey $\mathrm{E}$, et al. In vivo delivery of lentiviral vectors expressing vasoactive intestinal peptide complementary DNA as gene therapy for collagen-induced arthritis. Arthritis Rheum. (2008) 58, 1026-1037. doi: 10.1002/art.23283

54. Vessillier S, Adams G, Montero-Melendez T, Jones R, Seed M, Perretti $M$, et al. Molecular engineering of short half-life small peptides (VIP, alphaMSH and gamma(3)MSH) fused to latencyassociated peptide results in improved anti-inflammatory therapeutics. Ann Rheum Dis. (2012) 71:143-9. doi: 10.1136/annrheumdis-2011-2 00100

55. Colwell CS, Michel S, Itri J, Rodriguez W, Tam J, Lelievre V, et al. Disrupted circadian rhythms in VIP- and PHI-deficient mice. Am J Physiol Regul Integr Comp Physiol. (2003) 285:R939-49. doi: 10.1152/ajpregu.00200.2003

56. Abad C, Tan YV. Immunomodulatory roles of PACAP and VIP: lessons from knockout mice. J Mol Neurosci. (2018) 66:102-13. doi: 10.1007/s12031-018-1150-y

57. Abad C, Tan YV, Cheung-Lau G, Nobuta H, Waschek JA. VIP deficient mice exhibit resistance to lipopolysaccharide induced endotoxemia with an intrinsic defect in proinflammatory cellular responses. PLOS ONE. (2012) 7:e36922. doi: 10.1371/journal.pone.0036922

58. Vu JP, Million M, Larauche M, Luong L, Norris J, Waschek JA, et al. Inhibition of vasoactive intestinal polypeptide (VIP) induces resistance to dextran sodium sulfate (DSS)-induced colitis in mice. J Mol Neurosci. (2014) 52:37-47. doi: 10.1007/s12031-013-0205-3

59. Abad C, Cheung-Lau G, Coute-Monvoisin AC, Waschek JA. Vasoactive intestinal peptide-deficient mice exhibit reduced pathology in trinitrobenzene sulfonic acid-induced colitis. Neuroimmunomodulation. (2015) 22:203-12. doi: 10.1159/000364912

60. Orr C, Vieira-Sousa E, Boyle DL, Buch MH, Buckley CD, Canete JD, et al. Synovial tissue research: a state-of-the-art review. Nat Rev Rheumatol. (2017) 13: 463-75. doi: 10.1038/nrrheum.2017.161

61. Mcgettrick HM, Butler LM, Buckley CD, Rainger GE, Nash GB. Tissue stroma as a regulator of leukocyte recruitment in inflammation.J Leukoc Biol. (2012) 91:385-400. doi: 10.1189/jlb.0911458

62. Firestein GS, Mcinnes IB. Immunopathogenesis of rheumatoid arthritis. Immunity. (2017) 46:183-96. doi: 10.1016/j.immuni.2017. 02.006

63. Neumann E, Lefevre S, Zimmermann B, Geyer M, Lehr A, Umscheid T, et al. Migratory potential of rheumatoid arthritis synovial fibroblasts: additional perspectives. Cell Cycle. (2010) 9:2286-91. doi: 10.4161/cc.9.12.11907

64. Ospelt C. Synovial fibroblasts in 2017. RMD Open. (2017) 3:e000471. doi: 10.1136/rmdopen-2017-000471

65. Juarranz MG, Santiago B, Torroba M, Gutierrez-Canas I, Palao G, Galindo $\mathrm{M}$, et al. Vasoactive intestinal peptide modulates proinflammatory mediator synthesis in osteoarthritic and rheumatoid synovial cells. Rheumatology. (2004) 43:416-22. doi: 10.1093/rheumatology/keh061

66. Arranz A, Gutierrez-Canas I, Carrion M, Juarranz Y, Pablos JL, Martinez C, et al. VIP reverses the expression profiling of TLR4-stimulated signaling pathway in rheumatoid arthritis synovial fibroblasts. Mol Immunol. (2008) 45:3065-73. doi: 10.1016/j.molimm.2008.03.011

67. Carrion M, Juarranz Y, Perez-Garcia S, Jimeno R, Pablos JL, Gomariz RP, et al. RNA sensors in human osteoarthritis and rheumatoid arthritis synovial fibroblasts: immune regulation by vasoactive intestinal peptide. Arthritis Rheum. (2011) 63:1626-36. doi: 10.1002/art.30294

68. Carrion M, Perez-Garcia S, Jimeno R, Juarranz Y, Gonzalez-Alvaro I, Pablos $\mathrm{JL}$, et al. Inflammatory mediators alter interleukin-17 receptor, interleukin12 and -23 expression in human osteoarthritic and rheumatoid arthritis synovial fibroblasts: immunomodulation by vasoactive intestinal Peptide. Neuroimmunomodulation. (2013) 20:274-84. doi: 10.1159/000350892

69. Takeba Y, Suzuki N, Kaneko A, Asai T, Sakane T. Evidence for neural regulation of inflammatory synovial cell functions by secreting calcitonin gene-related peptide and vasoactive intestinal peptide in patients with rheumatoid arthritis. Arthritis Rheum. (1999) 42:2418-29. doi: 10.1002/1529-0131(199911)42:11<2418::AID-ANR21>3.0.CO;2-7

70. Dakin SG, Coles M, Sherlock JP, Powrie F, Carr AJ, Buckley CD. Pathogenic stromal cells as therapeutic targets in joint inflammation. Nat Rev Rheumatol. (2018) 14:714-26. doi: 10.1038/s41584-018-0112-7

71. Mulherin D, Fitzgerald O, Bresnihan B. Synovial tissue macrophage populations and articular damage in rheumatoid arthritis. Arthritis Rheum. (1996) 39:115-24. doi: 10.1002/art.1780390116

72. Ospelt C, Gay S. The role of resident synovial cells in destructive arthritis. Best Pract Res Clin Rheumatol. (2008) 22:239-52. doi: 10.1016/j.berh.2008.01.004

73. Haringman JJ, Gerlag DM, Zwinderman AH, Smeets TJ, Kraan MC, Baeten D, et al. Synovial tissue macrophages: a sensitive biomarker for response to treatment in patients with rheumatoid arthritis. Ann Rheum Dis. (2005) 64:834-8. doi: 10.1136/ard.2004.029751

74. Soler Palacios B, Estrada-Capetillo L, Izquierdo E, Criado G, Nieto C, Municio $\mathrm{C}$, et al. Macrophages from the synovium of active rheumatoid arthritis exhibit an activin A-dependent pro-inflammatory profile. J Pathol. (2015) 235:515-26. doi: 10.1002/path.4466

75. Dewit D, Gourlet P, Amraoui Z, Vertongen P, Willems F, Robberecht P, et al. The vasoactive intestinal peptide analogue RO25-1553 inhibits the production of TNF and IL-12 by LPS-activated monocytes. Immunol Lett. (1998) 60:57-60. doi: 10.1016/S0165-2478(97)00129-6

76. Burian B, Storka A, Marzluf BA, Yen YC, Lambers C, Robibaro B, et al. Vasoactive intestinal peptide (VIP) receptor expression in monocytederived macrophages from COPD patients. Peptides. (2010) 31:603-8. doi: 10.1016/j.peptides.2009.12.014

77. Storka A, Burian B, Fuhrlinger G, Clive B, Sun T, Crevenna R, et al. VPAC1 receptor expression in peripheral blood mononuclear cells in a human endotoxemia model. J Transl Med. (2013) 11:117. doi: 10.1186/1479-5876-11-117

78. Carrion M, Perez-Garcia S, Martinez C, Juarranz Y, Estrada-Capetillo L, Puig-Kroger A, et al. VIP impairs acquisition of the macrophage proinflammatory polarization profile. J Leukoc Biol. (2016) 100:1385-93. doi: 10.1189/jlb.3A0116-032RR

79. Lara-Marquez M, O'dorisio M, O'dorisio T, Shah M, Karacay B. Selective gene expression and activation-dependent regulation of vasoactive intestinal peptide receptor type 1 and type 2 in human T cells. J Immunol. (2001) 166:2522-30. doi: 10.4049/jimmunol.166.4.2522

80. Zhu J, Yamane H, Paul WE. Differentiation of effector CD4 T cell populations. Annu Rev Immunol. (2010) 28:445-89. doi: 10.1146/annurev-immunol-030409-101212

81. Zhu J. T helper cell differentiation, heterogeneity, and plasticity. Cold Spring Harb Perspect Biol. (2018) 10. doi: 10.1101/cshperspect.a030338

82. Malmstrom V, Catrina AI, Klareskog L. The immunopathogenesis of seropositive rheumatoid arthritis: from triggering to targeting. Nat Rev Immunol. (2017) 17:60-75. doi: 10.1038/nri.2016.124

83. Chemin K, Gerstner C, Malmstrom V. Effector functions of CD4+ T cells at the site of local autoimmune inflammation-lessons from rheumatoid arthritis. Front Immunol. (2019) 10:353. doi: 10.3389/fimmu.2019.00353

84. Kotake S, Yago T, Kobashigawa T, Nanke Y. The plasticity of Th17 cells in the pathogenesis of rheumatoid arthritis. J Clin Med. (2017) 6:67. doi: $10.3390 / j \mathrm{~cm} 6070067$

85. Van Hamburg JP, Tas SW. Molecular mechanisms underpinning $\mathrm{T}$ helper 17 cell heterogeneity and functions in rheumatoid arthritis. J Autoimmun. (2018) 87:69-81. doi: 10.1016/j.jaut.2017.12.006

86. Jimeno R, Leceta J, Martinez C, Gutierrez-Canas I, Carrion M, PerezGarcia $S$, et al. Vasoactive intestinal peptide maintains the nonpathogenic profile of human th17-polarized cells. J Mol Neurosci. (2014) 54:512-25. doi: 10.1007/s12031-014-0318-3

87. Yasuda K, Takeuchi Y, Hirota K. The pathogenicity of Th17 cells in autoimmune diseases. Semin Immunopathol. (2019) 41:283-97. doi: 10.1007/s00281-019-00733-8 
88. Leceta J, Gomariz RP, Martinez C, Carrion M, Arranz A, Juarranz Y. Vasoactive intestinal peptide regulates Th17 function in autoimmune inflammation. Neuroimmunomodulation. (2007) 14:134-8. doi: $10.1159 / 000110636$

89. Villanueva-Romero R, Gutierrez-Canas I, Carrion M, Perez-Garcia S, Seoane IV, Martinez C, et al. The anti-inflammatory mediator, vasoactive intestinal peptide, modulates the differentiation and function of Th subsets in rheumatoid arthritis. J Immunol Res. (2018) 2018:6043710. doi: $10.1155 / 2018 / 6043710$

90. Gutierrez-Canas I, Juarranz Y, Santiago B, Martinez C, Gomariz RP, Pablos $\mathrm{JL}$, et al. Immunoregulatory properties of vasoactive intestinal peptide in human T cell subsets: implications for rheumatoid arthritis. Brain Behav Immun. (2008) 22:312-7. doi: 10.1016/j.bbi.2007.09.007

91. Jimeno R, Gomariz RP, Garin M, Gutierrez-Canas I, Gonzalez-Alvaro I, Carrion $\mathrm{M}$, et al. The pathogenic Th profile of human activated memory Th cells in early rheumatoid arthritis can be modulated by VIP. J Mol Med. (2015) 93:457-67. doi: 10.1007/s00109-014-1232-4

92. Jimeno R, Leceta J, Garin M, Ortiz AM, Mellado M, Rodriguez-Frade JM, et al. Th17 polarization of memory Th cells in early arthritis: the vasoactive intestinal peptide effect. J Leukoc Biol. (2015) 98:257-69. doi: 10.1189/jlb.3A0714-327R

93. Delgado M, Martinez C, Johnson MC, Gomariz RP, Ganea D. Differential expression of vasoactive intestinal peptide receptors 1 and 2 (VIP-R1 and VIP-R2) mRNA in murine lymphocytes. J Neuroimmunol. (1996) 68:27-38. doi: 10.1016/0165-5728(96)00063-X

94. Goetzl EJ. Hypothesis: VPAC G protein-coupled receptors for vasoactive intestinal peptide constitute a dynamic system for signaling $\mathrm{T}$ cells from plasma membrane and nuclear membrane complexes. Regul Pept. (2006) 137:75-8. doi: 10.1016/j.regpep.2006.04.022

95. Lau CS, Chia F, Harrison A, Hsieh TY, Jain R, Jung SM, et al. APLAR rheumatoid arthritis treatment recommendations. Int J Rheum Dis. (2015) 18:685-713. doi: 10.1111/1756-185X.12754

96. Singh JA, Saag KG, Bridges SLJr, Akl EA, Bannuru RR, Sullivan MC, et al. 2015 American college of rheumatology guideline for the treatment of rheumatoid arthritis. Arthritis Rheumatol. (2016) 68:1-26. doi: 10.1002/art.39480

97. Smolen JS, Landewe R, Bijlsma J, Burmester G, Chatzidionysiou K, Dougados $\mathrm{M}$, et al. EULAR recommendations for the management of rheumatoid arthritis with synthetic and biological disease-modifying antirheumatic drugs: 2016 update. Ann Rheum Dis. (2017) 76:960-77. doi: 10.1136/annrheumdis-2016-210715

98. Smolen JS, Aletaha D, Barton A, Burmester GR, Emery P, Firestein GS, et al. Rheumatoid arthritis. Nat Rev Dis Primers. (2018) 4:18001. doi: $10.1038 / \mathrm{nrdp} .2018 .1$

99. Morice A, Unwin RJ, Sever PS. Vasoactive intestinal peptide causes bronchodilatation and protects against histamine-induced bronchoconstriction in asthmatic subjects. Lancet. (1983) 2:1225-7. doi: 10.1016/S0140-6736(83)91272-2

100. Henning RJ, Sawmiller DR. Vasoactive intestinal peptide: cardiovascular effects. Cardiovasc Res. (2001) 49:27-37. doi: 10.1016/S0008-6363(00)00229-7

101. Onyuksel H, Jeon E, Rubinstein I. Nanomicellar paclitaxel increases cytotoxicity of multidrug resistant breast cancer cells. Cancer Lett. (2009) 274:327-30. doi: 10.1016/j.canlet.2008.09.041

102. Koo OM, Rubinstein I, Onyuksel H. Actively targeted lowdose camptothecin as a safe, long-acting, disease-modifying nanomedicine for rheumatoid arthritis. Pharm Res. (2011) 28:776-87. doi: 10.1007/s11095-010-0330-4

103. Smolen JS, Aletaha D. Rheumatoid arthritis therapy reappraisal: strategies, opportunities and challenges. Nat Rev Rheumatol. (2015) 11:276-89. doi: $10.1038 /$ nrrheum.2015.8
104. Martinez C, Ortiz AM, Juarranz Y, Lamana A, Seoane IV, Leceta J, et al. Serum levels of vasoactive intestinal peptide as a prognostic marker in early arthritis. PLoS ONE. (2014) 9:e85248. doi: 10.1371/journal.pone. 0085248

105. Mihara M, Ohsugi Y, Kishimoto T. Tocilizumab, a humanized antiinterleukin-6 receptor antibody, for treatment of rheumatoid arthritis. Open Access Rheumatol. (2011) 3:19-29. doi: 10.2147/OARRR.S17118

106. Shimamoto K, Ito T, Ozaki Y, Amuro H, Tanaka A, Nishizawa T, et al. Serum interleukin 6 before and after therapy with tocilizumab is a principal biomarker in patients with rheumatoid arthritis. J Rheumatol. (2013) 40:1074-81. doi: 10.3899/jrheum.121389

107. Kirwan JR, Hewlett SE, Heiberg T, Hughes RA, Carr M, Hehir M, et al. Incorporating the patient perspective into outcome assessment in rheumatoid arthritis-progress at OMERACT 7. J Rheumatol. (2005) 32:2250-6.

108. Heiberg T, Kvien TK, Mowinckel P, Aletaha D, Smolen JS, Hagen KB. Identification of disease activity and health status cut-off points for the symptom state acceptable to patients with rheumatoid arthritis. Ann Rheum Dis. (2008) 67:967-71. doi: 10.1136/ard.2007.0 77503

109. Aletaha D, Funovits J, Ward MM, Smolen JS, Kvien TK. Perception of improvement in patients with rheumatoid arthritis varies with disease activity levels at baseline. Arthritis Rheum. (2009) 61:313-20. doi: 10.1002/art.24282

110. Felson DT, Smolen JS, Wells G, Zhang B, Van Tuyl LH, Funovits J, et al. American College of Rheumatology/European League Against Rheumatism provisional definition of remission in rheumatoid arthritis for clinical trials. Arthritis Rheum. (2011) 63:573-86. doi: 10.1002/art.30129

111. Combe B, Landewe R, Lukas C, Bolosiu HD, Breedveld F, Dougados M, et al. EULAR recommendations for the management of early arthritis: report of a task force of the European Standing Committee for International Clinical Studies Including Therapeutics (ESCISIT). Ann Rheum Dis. (2007) 66:34-45. doi: 10.1136/ard.2005.044354

112. Smolen JS, Landewe R, Breedveld FC, Dougados M, Emery P, GaujouxViala C, et al. EULAR recommendations for the management of rheumatoid arthritis with synthetic and biological disease-modifying antirheumatic drugs. Ann Rheum Dis. (2010) 69:964-75. doi: 10.1136/ard.2009.126532

113. Keystone EC, Smolen J, Van Riel P. Developing an effective treatment algorithm for rheumatoid arthritis. Rheumatology. (2012) 51(Suppl. 5):v4854. doi: 10.1093/rheumatology/kes122

114. Robinson WH, Mao R. Biomarkers to guide clinical therapeutics in rheumatology? Curr Opin Rheumatol. (2016) 28:168-75. doi: 10.1097/BOR.0000000000000250

115. Castrejon I, Ortiz AM, Garcia-Vicuna R, Lopez-Bote JP, Humbria A, Carmona L, et al. Are the C-reactive protein values and erythrocyte sedimentation rate equivalent when estimating the 28 -joint disease activity score in rheumatoid arthritis? Clin Exp Rheumatol. (2008) 26:769-75.

Conflict of Interest: The authors declare that the research was conducted in the absence of any commercial or financial relationships that could be construed as a potential conflict of interest.

Copyright (C) 2019 Gomariz, Juarranz, Carrión, Pérez-García, Villanueva-Romero, González-Álvaro, Gutiérrez-Cañas, Lamana and Martínez. This is an open-access article distributed under the terms of the Creative Commons Attribution License (CC $B Y)$. The use, distribution or reproduction in other forums is permitted, provided the original author(s) and the copyright owner(s) are credited and that the original publication in this journal is cited, in accordance with accepted academic practice. No use, distribution or reproduction is permitted which does not comply with these terms. 